\title{
Relationship between anticipatory postural adjustment of the trunk, dual tasks and physical performance with chronic stroke survivors: a pilot test
}

\author{
Won Jeong Hwanga ${ }^{a}$ Min Kwon Choa, Yijung Chung ${ }^{b}$ \\ aDepartment of Physical Therapy, The Graduate School of Sahmyook University, Seoul, Republic of Korea \\ ${ }^{\mathrm{b}}$ Department of Physical Therapy, College of Health and Welfare, Sahmyook University, Seoul, Republic of Korea
}

Objective: The purpose of this study was to investigate the relationship between anticipatory postural adjustment (APA), single task, dual tasks and physical performances. The trunk muscles of APA consist of bilateral erector spinae (ES) and bilateral internal oblique (IO) adnominal muscles, during rapid stepping with the affected or unaffected leg in a sitting posture.

Design: Cross-sectional study.

Methods: In patients with chronic stroke, electrodes of surface electromyography (EMG) were attached on the bilateral erector spinae (ES), bilateral internal oblique adnominal (IO), and bilateral rectus femoris (RF) muscles. RF acts as the prime mover. The stroke patients performed hip flexion until $20^{\circ}$ as fast as possible at each leg in a sitting posture according to a visual cue. The visual cue unexpectedly appeared on monitor in front of the stroke patient. The single task was the Timed Up and Go (TUG) test. The dual tasks were the TUGconitive, which increased cognitive capacity, and the TUGmanual task, which had an external focus.

Results: All EMG data showed earlier onset latency before the prime mover. In affected leg raising, the onset time of unaffected ES muscle of the stroke patients was correlated with the single and dual tasks $(p<0.05)$. In unaffected leg raising, the onset time of the affected IO muscle was related to all the tasks $(p<0.05)$. Gait speed showed a relationship with the unaffected ES muscle only. Conclusions: The trunk muscles of the bilateral ES and bilateral IO play an important role in APA. The single and dual tasks using TUG test were correlated with the APA s of ES and IO muscles. Dual task by the TUG test is a good measuring tool for reflecting the real life in patients with chronic stroke.

Key Words: Postural balance, Stroke, Test

\section{Introduction}

Stroke survivors have balance deficits that increase their risk of falling. The incidence rate of falling in patients with chronic stroke was revealed to be between $23 \%$ and $50 \%$ [1-3]. Furthermore, it is associated with quality of life [4]. The most common method for preventing falls is compensatory balance reaction [5], which involves searching for a new base of support through rapid stepping or grasping [6]. Stepping is a commonly used method to gain balance by utilizing extremity. In particular, stroke patients prefer the use of the less-affected limb than the affected limb for compensatory stepping. Rapid stepping is fundamental skill to prevent falling, but a previous study showed delayed stepping among [7].

The function of trunk muscle was to maintain posture and enable movement of the limbs. Generally, the activity of the trunk muscle such as the transversus abdominis (TrA), internal oblique (IO) abdominal, and rectus abdominis (RA) muscles occur before movement of lower limb in varied directions among healthy people. Spine stability is maintained by the central nervous system (CNS) [8]. Anticipatory pos-

Received: 6 May, 2015 Revised: 10 June, 2015 Accepted: 11 June, 2015

Corresponding author: Yijung Chung

Department of Physical Therapy, College of Health and Welfare, Sahmyook University, 815 Hwarang-ro, Nowon-gu, Seoul 139-742, Republic of Korea Tel: 82-2-3399-1637 Fax: 82-2-3399-1639 E-mail: yijung36@syu.ac.kr

(c) This is an Open-Access article distributed under the terms of the Creative Commons Attribution Non-Commercial License (http://creativecommons.org/licens es/by-nc/4.0) which permits unrestricted non-commercial use, distribution, and reproduction in any medium, provided the original work is properly cited.

Copyright $@ 2015$ Korean Academy of Physical Therapy Rehabilitation Science 
tural adjustment (APA) is achieved through the muscle activities before focal movement or perturbation, and feed-forward mechanism of the CNS [9]. Trunk impairment generally accompanies stroke. A study on stroke revealed delayed time of muscle activity of the affected side [10]. Other study has shown different onset latency of trunk muscles between the paretic and nonparetic sides in the sitting posture [11]. In an asymmetrical posture, the erector spinae (ES) muscle on the posterior trunk muscle was showed early activation before performance [12].

Many studies were conducted on APA in the sitting and standing static posture. However, dynamic posture such as that in walking carries a higher risk of falling than static posture. Walking requires cognitive functions. Elderly people showed delayed stepping in dual task $[13,14]$. Dual task was more effective than single for balance training among stroke patients [15]. Type of dual task was divided according to different concentration. One was focused on motor function, which was considerate as the external focus. In this task, the stroke patient walked while holding a cup using unaffected hand. The other focus area was on cognition, in which the task involves counting backward [16].

The purpose of the study was to investigate the APA of anterior and posterior trunk muscle during rapid stepping of each leg in sitting posture and investigate their association with various dual tasks and physical performance.

\section{Methods}

\section{Subjects}

Stroke participants at a rehabilitation hospital who understood the purpose of the study were recruited. The inclusion criteria were as follows: first stroke, at least 6 months after stroke, Brunnstrom recovery stage 3 or 4 , gait ability over about 10 meter without assistive devices, and Korean version of mini-mental state examination score higher than 20 . The exclusion criteria were as follows: musculoskeletal problems, pain, and inability to raise one leg without assistive devices. All of subjects signed a consent form. All study procedures were approved by the Sahmyook University institutional review board.

\section{Methods}

The stroke survivors sat in chair without backrest maintaining an upright posture. They flexed their hip and knee by $90^{\circ}$ and posited their feet on the floor. A monitor was placed in front of the subject, 1 meter away and at eye level. The

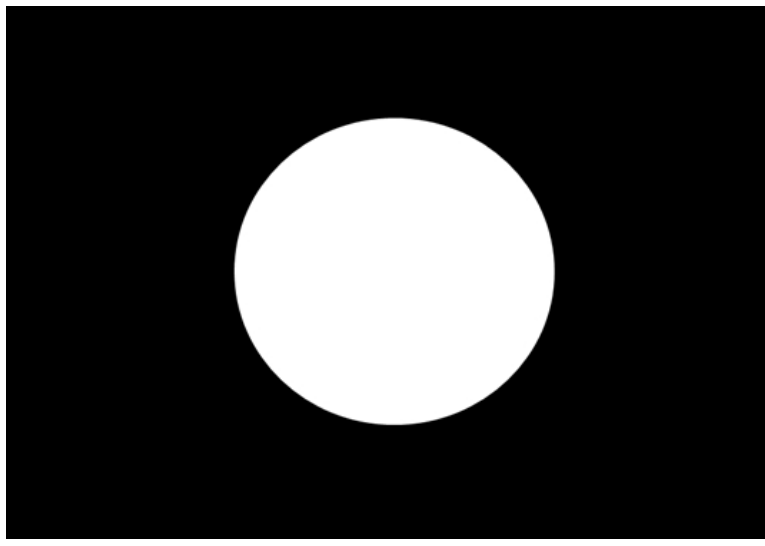

Figure 1. Visual cue in the monitor.

monitor showed a block background and unexpectedly showed a white circle as the visual cue, which is shown Figure 1. The subjects flexed their hip by $20^{\circ}$ on either side as fast as possible according to the visual cue. Measurements were performed three times each on affected and unaffected legs.

Electromyographic data were collected for onset latency of the trunk muscles such as the bilateral lumbar ES, bilateral IO and bilateral rectus femoris (RF) muscles. RF was the prime mover muscle. Bilateral surface electrodes were used to collect data. The lumbar ES was located $3 \mathrm{~cm}$ lateral to the spine, between the L3 and L4 vertebrae levels [17]. IO was located approximately $2 \mathrm{~cm}$ medial and inferior to the anterior superior iliac spine (ASIS) [18]. RF was located halfway between ASIS and patella. Noise from electromyography (EMG) signals was eliminated by using a $60-\mathrm{Hz}$ notch filer. Smoothness was achieved by using a low-pass filter. Onset latency was calculated to exceed 2 standard deviations (SDs) within $50 \mathrm{~ms}$ of baseline while maintaining $30 \mathrm{~ms}$ [11]. The feed-forward mechanism of each muscle was defined by the time. It took the EMG signals to change from before $100 \mathrm{~ms}$ to after $50 \mathrm{~ms}$ [19].

Physical performances were measured by using 10-meter walk test (10MWT), Berg Balance Scale (BBS), and Time Up and Go (TUG) test. TUG test is single task. Dural task performance was measured during TUGmanual and TUGcognitive tasks. The subjects perfectly executed the TUG task with the TUGmanual task of holding a cup filled the water. The stroke patients were asked not to spill the water on the floor. The TUG test was completed with the TUGcongnitive task while counting backward by threes [16]. The stroke patients were able to perform twice counting backward within TUGcognitive task. The first number 
of counting backward was randomly provided by the physical therapist. The number was provided between 80 and 99 .

\section{Data analysis}

This study used PASW Statistics ver. 18.0 (IBM Co., Armonk, NY, USA) in the statistical analysis. Onset latency of bilateral trunk muscles was shown as mean and SD values by using descriptive statistics. Correlation between variables was determined by performing a Spearman correlation analysis. The significance level was $p<0.05$.

\section{Results}

The stroke patients showed high BBS level (52.14 [4.30]). TUG (16.66 [7.74]) was completed faster than the TUGcognitive task (18.27 [8.69]) and TUGmanual task (19.24 [9.86]) Table 1. The bilateral ES and bilateral IO trunk muscles revealed that onset latency was faster than prime mover. The IO responded faster than the ES during affected-leg raising. However, this was not the case during unaffected-leg rasing. The affected side between ES $(-0.28$ [0.33]) and IO ( $-0.27[0.26])$ responded faster than unaffected side at IO ( $-0.22[0.25])$ and ES $(-0.01[0.30]$; Table 2).

TUG test, TUGcognitive, and TUGmanual were related to the APA of trunk muscles. The relationship was demonstrated at the unaffected ES during affected-leg raising. Only

Table 1. General characteristics of the subjects

$(\mathrm{N}=7)$

\begin{tabular}{lc}
\hline Characteristic & Variable \\
\hline Gender (male/female) & $5 / 2$ \\
MMSE-K & $24.86(2.73)$ \\
10-meter walk test & $15.21(8.63)$ \\
Berg Balance Scale & $52.14(4.30)$ \\
Timed Up and Go & $16.66(7.74)$ \\
TUGcongnitive & $18.27(8.69)$ \\
TUGmanual & $19.24(9.86)$ \\
\hline
\end{tabular}

Values are presented as $\mathrm{n}$ or mean (SD).

MMSE-K: Korean version of mini-mental state examination. the IO of the affected side showed a relationship with performance in unaffected-leg raising. The performance in the 10MWT was correlated with only ES of the unaffected side during affected-leg raising (Table 3).

\section{Discussion}

Rapid stepping is an important strategy for recovering balance in order to prevent falling. Stepping among stroke patients was reportedly delayed because the decreased muscle power of the affected leg compared with that of the unaffected leg. The muscle powers of the ankle plantar-flexors and hip flexor of affected leg during swing phase were inadequately because of paralysis [20].

APA provides postural control during voluntary movements. It occurs before limb movement or disturbance to maintain equilibrium [9]. APA involves basal ganglia, supplementary motor area, and motor cortex. APA is achieved through the feed-forward mechanism of the CNS $[9,21]$. APA is interrupted by damage to the CNS. The trunk plays an important part in maintaining postural balance. TrA, IO and RA muscles were activated earlier than prime mover, regardless of the lower limb directions [8]. In this study, the bilateral IO muscles were activated before the prime mover, regardless of the affected or unaffected leg. Early onset latency of TrA/IO muscle appeared during shoulder ex-

Table 3. Relationship between onset latency of trunk muscles, dual task, and physical performances

\begin{tabular}{lcc}
\hline & $\begin{array}{c}\text { Raised } \\
\text { affected leg } \\
\text { nES }\end{array}$ & $\begin{array}{c}\text { Raised } \\
\text { unaffected leg } \\
\text { aIO }\end{array}$ \\
\hline TUG (sec) & $0.829^{*}$ & $0.857^{*}$ \\
TUGcongnitive (sec) & $0.829^{*}$ & $0.857^{*}$ \\
TUGmanual (sec) & $0.829^{*}$ & $0.857^{*}$ \\
10-meter walk test (sec) & $0.829^{*}$ & \\
\hline
\end{tabular}

nES: erector spinae muscle of unaffected side, aIO: internal oblique abdominal muscle of affected side. ${ }^{*} p 0.05$.

Table 2. Onset latency of trunk muscles

\begin{tabular}{lcccc} 
& Affected side & Unaffected side & Affected side & \multicolumn{2}{c}{ Unaffected side } \\
& ES & ES & IO & IO \\
\hline Raise affected leg & $-0.16(0.24)$ & $-0.10(0.33)$ & $-0.36(0.20)$ & $-0.22(0.31)$ \\
Raise unaffected leg & $-0.28(0.33)$ & $-0.01(0.30)$ & $-0.27(0.26)$ & $-0.22(0.25)$ \\
\hline
\end{tabular}

Values are presented as mean (SD).

ES: erector spinae, IO: internal oblique. 
tension, and all onset latencies of $\mathrm{TrA} / \mathrm{IO}$ were activated in the APA phase [18]. Symmetry stance, left asymmetry stance, and right asymmetry stance in the early onset latency of the ES muscle were investigated during load-release tasks with healthy people [12]. In stroke patients, the bilateral ES muscles provided onset latency into APA phase during shoulder flexion in sitting posture [11]. In this study, the onset latency of the bilateral ES muscles was earlier than that of the prime mover. According to affected and unaffected leg, the arrangements of onset latency varied. However, all data existed before onset time of prime mover. For example, early activation of bilateral IO and ES muscles maybe serve to recover balance during leg raising via feed-forward mechanism.

Stroke patients have cognitive function deficit. The most common cognitive deficit is attention. Attention deficit affects the recovery of stroke patients [22]. Attention is usually required in all activities of daily living, especially in multitasking such as walking while conversing. A previous study was compared single and dual tasks [23]. Dual task with cognitive task increased attention capacity during postural control. Balance was better in the dual task than in the single task [24]. In this study, the performance time of the cognitive dual task was longer the than that of the TUG test alone. A dual task with an external focus is important. External focus concentrates on movement itself to receive information from the resulting movement [25]. Dual task with the TUGmanual task is better measurement than the single test in the TUG test. The TUGmanual task is a good tool with high validity and sensitivity [16]. In this study, The TUGmanual task took more time than the TUGcognitive task and TUG test, although both TUGcognitive and TUGmanual tasks were required more time. This was affected by the environment of the subject in real life.

The core muscle is involved in stability and movements. The ES and IO muscles are core muscles. The trunk which includes with ES and IO muscles, contributes to maintaining posture, and leg and arm movements [26]. In addition, the trunk plays a role in the APA. In stroke patients with trunk impairments, the single and dual tasks with TUG were related to the APAs of ES and IO muscles. The APA of unaffected ES and affected IO muscles were strongly related to the tasks. Gait speed correlated with only APA of the global trunk muscle.

APA is important with stroke patients. While moving the limbs, maintaining balance in a various environments is very important. That should help to prevent a fall. In this study, APA of trunk muscles was showed by onset latency while stepping in stroke patients. That was correlated with single and dual tasks. Dual task was required multitask performance. The real life mirrors the surrounding environments. And there is mostly multitasking. Stroke patients evaluate the ability to balance using TUG test. However, The TUG test is single task, which does not reflect various environments and multitasking. If you want a measure that reflects the real life, balance evaluation with stroke patients is advised to conduct dual task than single task. A Relationship between APA of trunk muscles, TUG test, dual test, and physical performance supports that dual task such as TUGcognitive and TUGmanual task is a good measurement tool.

This study includes small sample size. And there is limitation of trunk muscles. That limits the generalization.

\section{Conflict of Interest}

The authors declared no potential conflicts of interest with respect to the authorship and/or publication of this article.

\section{References}

1. Jørgensen L, Engstad T, Jacobsen BK. Higher incidence of falls in long-term stroke survivors than in population controls: depressive symptoms predict falls after stroke. Stroke 2002;33: 542-7.

2. Hyndman D, Ashburn A, Stack E. Fall events among people with stroke living in the community: circumstances of falls and characteristics of fallers. Arch Phys Med Rehabil 2002;83:165-70.

3. Hyndman D, Ashburn A. People with stroke living in the community: Attention deficits, balance, ADL ability and falls. Disabil Rehabil 2003;25:817-22.

4. Schmid AA, Van Puymbroeck M, Altenburger PA, Miller KK, Combs SA, Page SJ. Balance is associated with quality of life in chronic stroke. Top Stroke Rehabil 2013;20:340-6.

5. Maki BE, McIlroy WE. The role of limb movements in maintaining upright stance: the "change-in-support" strategy. Phys Ther 1997;77:488-507.

6. McIlroy WE, Maki BE. Task constraints on foot movement and the incidence of compensatory stepping following perturbation of upright stance. Brain Res 1993;616:30-8.

7. Lakhani B, Mansfield A, Inness EL, McIlroy WE. Compensatory stepping responses in individuals with stroke: a pilot study. Physiother Theory Pract 2011;27:299-309.

8. Hodges PW, Richardson CA. Contraction of the abdominal muscles associated with movement of the lower limb. Phys Ther 1997;77:132-42; discussion 142-4.

9. Massion J. Movement, posture and equilibrium: interaction and coordination. Prog Neurobiol 1992;38:35-56.

10. Garland SJ, Stevenson TJ, Ivanova T. Postural responses to uni- 
lateral arm perturbation in young, elderly, and hemiplegic subjects. Arch Phys Med Rehabil 1997;78:1072-7.

11. Dickstein R, Shefi S, Marcovitz E, Villa Y. Anticipatory postural adjustment in selected trunk muscles in post stroke hemiparetic patients. Arch Phys Med Rehabil 2004;85:261-7.

12. Aruin AS. The effect of asymmetry of posture on anticipatory postural adjustments. Neurosci Lett 2006;401:150-3.

13. Shumway-Cook A, Woollacott M. Attentional demands and postural control: the effect of sensory context. J Gerontol A Biol Sci Med Sci 2000;55:M10-6.

14. Brauer SG, Woollacott M, Shumway-Cook A. The influence of a concurrent cognitive task on the compensatory stepping response to a perturbation in balance-impaired and healthy elders. Gait Posture 2002;15:83-93.

15. Choi W, Lee G, Lee S. Effect of the cognitive-motor dual-task using auditory cue on balance of surviviors with chronic stroke: A pilot study. Clin Rehabil 2014. [Epub ahead of print]

16. Tang PF, Yang HJ, Peng YC, Chen HY. Motor dual-task Timed Up \& Go test better identifies prefrailty individuals than single-task Timed Up \& Go test. Geriatr Gerontol Int 2015; 15:20410.

17. Escamilla RF, Babb E, DeWitt R, Jew P, Kelleher P, Burnham T, et al. Electromyographic analysis of traditional and nontraditional abdominal exercises: implications for rehabilitation and training. Phys Ther 2006;86:656-71.

18. Marshall P, Murphy B. The validity and reliability of surface EMG to assess the neuromuscular response of the abdominal muscles to rapid limb movement. J Electromyogr Kinesiol 2003;13:477-89.

19. Aruin AS, Latash ML. Directional specificity of postural muscles in feed-forward postural reactions during fast voluntary arm movements. Exp Brain Res 1995;103:323-32.

20. Kirker SG, Simpson DS, Jenner JR, Wing AM. Stepping before standing: hip muscle function in stepping and standing balance after stroke. J Neurol Neurosurg Psychiatry 2000;68:458-64.

21. Massion J, Ioffe M, Schmitz C, Viallet F, Gantcheva R. Acquisition of anticipatory postural adjustments in a bimanual load-lifting task: normal and pathological aspects. Exp Brain Res 1999; 128:229-35.

22. Loetscher T, Lincoln NB. Cognitive rehabilitation for attention deficits following stroke. Cochrane Database Syst Rev 2013;5: CD002842.

23. Woollacott M, Shumway-Cook A. Attention and the control of posture and gait: a review of an emerging area of research. Gait Posture 2002;16:1-14.

24. Hyndman D, Ashburn A, Yardley L, Stack E. Interference between balance, gait and cognitive task performance among people with stroke living in the community. Disabil Rehabil 2006; 28:849-56.

25. McNevin NH, Wulf G. Attentional focus on supra-postural tasks affects postural control. Hum Mov Sci 2002;21:187-202.

26. Ryerson S, Byl NN, Brown DA, Wong RA, Hidler JM. Altered trunk position sense and its relation to balance functions in people post-stroke. J Neurol Phys Ther 2008;32:14-20. 